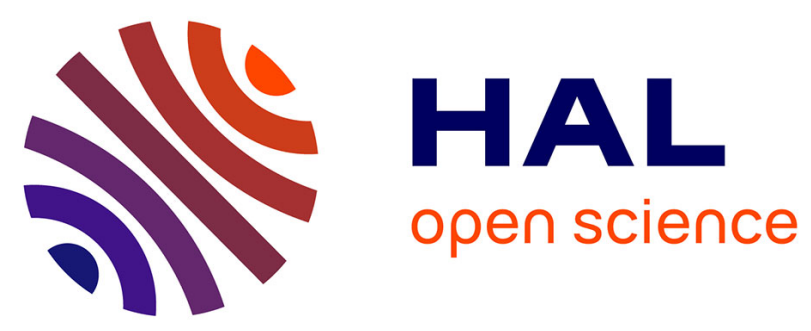

\title{
Yeast and bacteria from ensiled high moisture maize grains as potential mitigation agents of fumonisin B 1
}

Ccori Martinez Tuppia, Vessela Atanasova-Penichon, Sylvain Chéreau, Nathalie Ferrer, Gisele Marchegay, Jean-Michel Savoie, Florence Richard-Forget

\section{To cite this version:}

Ccori Martinez Tuppia, Vessela Atanasova-Penichon, Sylvain Chéreau, Nathalie Ferrer, Gisele Marchegay, et al.. Yeast and bacteria from ensiled high moisture maize grains as potential mitigation agents of fumonisin B 1. Journal of the Science of Food and Agriculture, 2017, 97 (8), pp.2443-2452. 10.1002/jsfa.8058 . hal-02156680

\section{HAL Id: hal-02156680 \\ https://hal.science/hal-02156680}

Submitted on 14 Jun 2019

HAL is a multi-disciplinary open access archive for the deposit and dissemination of scientific research documents, whether they are published or not. The documents may come from teaching and research institutions in France or abroad, or from public or private research centers.
L'archive ouverte pluridisciplinaire $\mathbf{H A L}$, est destinée au dépôt et à la diffusion de documents scientifiques de niveau recherche, publiés ou non, émanant des établissements d'enseignement et de recherche français ou étrangers, des laboratoires publics ou privés. 
YEAST AND BACTERIA FROM ENSILED HIGH MOISTURE MAIZE GRAINS AS POTENTIAL MITIGATION AGENTS OF FUMONISIN B1

Ccori Martinez Tuppia ${ }^{1,2}$, Vessela Atanasova-Penichon ${ }^{1}$, Sylvain Chéreau ${ }^{1}$, Nathalie Ferrer ${ }^{1}$, Gisèle Marchegay ${ }^{1}$, Jean-Michel Savoie ${ }^{1}$ and Florence Richard-Forget ${ }^{1 *}$

1 MycSA, Inra, 71 avenue Edouard Bourleaux, CS20032, F-33882 Villenave d'Ornon Cedex, France.

2 Lallemand Animal Nutrition, 19 rue des Briquetiers, B.P. 59, F-31702 Blagnac, France.

* Correspondance to : Florence Richard-Forget, MycSA, Inra, 71 avenue Edouard Bourleaux, CS20032, F-33882 Villenave d'Ornon Cedex, France E-mail: fforget@bordeaux.inra.fr

RUNNING TITLE: Maize grain silage as a source of FB1 degrading microorganisms

\begin{abstract}
BACKGROUND: Fumonisin B1 (FB1) is a mycotoxin produced by several Fusarium species and a very common contaminant of maize-based food and feed throughout the world. The selection and use of FB1-degrading microorganisms appears as a promising alternative to cope with the problem of toxicity towards humans and livestock. High moisture maize grain silage which is based on natural maize fermentation could be an interesting reservoir of such microorganisms.

RESULTS: Using an in vitro simulated silage model with FB1 naturally contaminated grains, we demonstrated a significant raw decrease in FB1 during ensiling process ascribed to biodegradation mechanisms. A panel of 98 bacteria and yeasts were isolated from this matrix and selected for their ability to use FB1 as the sole source of C and N. For nine of them, the ability to degrade FB1 in vitro was evidenced. Notably, two bacteria identified as Lactobacillus sp. were highlighted for their efficient FB1-degrading capacity and production of hydrolysed FB1 as intermediate degradation metabolite.
\end{abstract}


CONCLUSION: Fermentation of high moisture maize grain contaminated with FB1 leads to a significant reduction of the toxin and allows the isolation of FB1-degrading microorganisms that could further be used as FB1 decontaminating agents.

Keywords: Biodegradation, mycotoxin, Fumonisin B1, hydrolyzed FB1, silage.

\section{INTRODUCTION}

Maize is the world's most widely grown cereal. Its use significantly varies from country to country, with a percentage intended for human consumption ranging between $4 \%$ to $60 \%^{1}$ and the rest being used for feed and bioethanol. Maize is particularly prone to contamination with mycotoxins among which Fumonisins are dramatically worrying in regards to their toxicity to humans ${ }^{2}$ and animals. ${ }^{3,4}$ Fumonisins are mainly produced by Fusarium proliferatum and Fusarium verticillioides which are the two major fungal actors of Fusarium ear rot, one of the most common fungal diseases of maize. There are at least 28 different forms of Fumonisins, classified as belonging to class A, B, C, and P. Fumonisin B1 (FB1) which is the most common form, is a polyhydroxy alkyl amine, esterified on C14 and C15 with 2 molecules of tricarballylic acid (TCA). FB1 is mostly produced during pre-harvest ${ }^{5}$; however it can also be accidentally produced during post-harvest storage such as in the ensiling processes. ${ }^{6,7}$

Unfortunately, once produced, FB1 is highly stable and its detoxification by physical and chemical methods, authorized only in Europe for products intended for animal consumption, ${ }^{8}$ are limited due to partial efficiency and alteration of the matrix, including decrease of the nutrient content. ${ }^{9-11}$ Biological post-harvest treatments for mycotoxin removal might represent an alternative promising option to decrease FB1 content in maize products. These biological treatments include both adsorption and microbial degradation. ${ }^{12}$ Adsorption can result from the binding of FB1 with cell wall components of microorganisms, which is largely documented in the literature. ${ }^{13-16}$ Moreover, during the biological postharvest treatments of maize, FB1 binding can also involve the formation of covalent bonds with maize components or the physical entrapment of the toxin into macromolecules such as starch. ${ }^{17}$ Since bound or entrapped into macromolecules forms of FB1 may be difficult to detect using conventional analytical 
procedures, they have been commonly designed as hidden or masked fumonisins. ${ }^{17}$ But, according to Rychlik et al. ${ }^{18}$ the term matrix-associated fumonisins may be more suitable to encompass all possible forms of interactions, both physical and chemical ones. The capacity of numerous organic and inorganic compounds to bind mycotoxins has led to the release of a large panel of feed additives marketed as mycotoxin binders which use aims to reduce mycotoxin availability, uptake and toxicity to livestock. ${ }^{19}$ Two main adverse effects require however to be considered when using FB1-binders: (i) the binders can interact with other nutrients and feed compounds, (ii) the mycotoxin-complexes are reversible under some physicochemical conditions and the toxins are prone to be released in the digestive tract of consumers. ${ }^{10}$

In addition to adsorption mechanisms, biological treatments can also exploit the occurrence of microbial enzymatic activities capable to transform FB1 into less or non-toxic metabolites ${ }^{11,20,21}$ giving therefore the guarantee of a lower risk. The occurrence of microorganisms able to metabolize mycotoxins has been the subject of several publications. ${ }^{10,21-26}$ As regards to FB1, bacteria and fungi reported and/or patented as able to degrade the toxin have been mainly isolated from field grown maize stalk $^{22-24}$ or soil. ${ }^{27,28}$ FB1 degradation through microbial activities usually involves a decarboxylation reaction that cleaves the two TCA moieties from $\mathrm{C} 14$ and $\mathrm{C} 15$ of the main chain converting FB1 into hydrolysed fumonisin B1 (HFB1). The lowest toxicity of HFB1 compared to that of FB1 was recently evidenced by Grenier et al. ${ }^{29} \mathrm{~A}$ further deamination of HFB1 by an aminooxidase, ${ }^{22-24,} 30$ an aminotransferase,$^{31,32}$ a deaminase ${ }^{33}$ or an aminomutase ${ }^{33}$ may also occur. Nonetheless, most of these microbial activities involve molecular oxygen independent ${ }^{34}$ or dependant ${ }^{24}$ reactions and require specific conditions such as the presence of specific co-substrates ${ }^{31,32,35}$ that could not be present in a specific food or feed product, including maize fermented products.

High moisture maize grain (HMMG) silage is based on the natural fermentation of whole or ground grains that are harvested shortly after the physiological maturity stage with an optimum dry matter content around $70 \% .{ }^{36}$ During the last decade, it has become a more ubiquitous practice in Europe since it can be easily processed on farms, represents an economic storage procedure (no grain drying costs are encountered) and leads to an interesting feed characterized by a high starch digestibility and nutritional value for livestock. ${ }^{37,38}$ To our knowledge, the fate of FB1 during HMMG ensiling process has not been 
documented while numerous studies have addressed the issue of whole maize plant silage contamination with mycotoxins. ${ }^{6,39-41}$ Interestingly, some of these studies have demonstrated that, in some cases, wellpreserved maize silage can lead to a significant decrease of FB1 levels (up to 90\%) after three months of fermentation. ${ }^{6}{ }^{39}$ Since maize grains composing HMMG silages have evolved in association with a diverse epiphytic and endophytic microbial community including both bacteria and fungi or yeast, ${ }^{42-44}$ it makes sense to assume that FB1 accumulated during maize culture may have led to the selection of some microorganisms able to degrade the toxin and that contaminated HMMG could represent an interesting reservoir of such microorganisms.

In an attempt to select new microorganisms for the mitigation of FB1 in maize, the aims of this study were (i) to provide baseline information on the potential for degrading FB1 of fermentation processes as it is performed in HMMG ensiling, (ii) to investigate HMMG as an efficient source of novel FB1 degrading microorganisms.

\section{MATERIALS AND METHODS}

\section{Maize samples and in vitro simulated silages}

Fusarium contaminated (presenting ear rot symptoms) and sound (with no ear rot symptoms) maize cobs of late yellow dent grain maize varieties were collected from different fields located in the southwest of France during two years of harvest (2011 and 2013). Maize grains were separated from cobs and coarsely ground. We used an in vitro simulated silage model, called mini-silos. A mini-silo consisted of PVC tubes (10 cm diameter, $50 \mathrm{~cm}$ high) which contained $3 \mathrm{~kg}$ of compacted ground grains. They were hermetically closed, and a valve at one end avoided over pressure.

First, to assess the FB1 evolution in contaminated maize grains during ensiling process, we prepared mini-silos using different proportions of contaminated and sound maize harvested in 2011. Four types of mini-silos were stablished: A (uniquely composed of sound maize), B-C (composed of $80 \%$ and $20 \%$ of sound and contaminated maize, respectively) and D (composed of $70 \%$ and $30 \%$ of sound and contaminated maize, respectively). Secondly, to confirm the results obtained with this first set of mini- 
silos and to isolate microorganisms able to degrade FB1, we prepared four additional set of mini-silos using contaminated grains from four French fields harvested in 2013: E, F, G, and H. The silos were placed in a room with temperatures varying from 18 to $25^{\circ} \mathrm{C}$ throughout the ensiling process. Mean moisture content in mini-silos was initially adjusted to $30 \%$ in all samples. A, B, C and D silages were analysed at three fermentation time points: day 0 , day 78 and day 141. E, F, G and H silages were analysed at four fermentation time points: day 0 , day 48 , day 82 and day 141 . These dates were chosen to be before ensiling, during the fermentation phase (day 48, 78 and 82 ) and during the storage phase (day 141). At each sampling time, one mini-silo per type of silage was opened and three samples of 200 g from different silage sections were collected for analysis. Finally, physicochemical parameters including $\mathrm{pH}$, and moisture contents were determined.

\section{Chemicals and reagents}

FB1 and HFB1 standard solutions were purchased from Biopure (Tulln, Austria). All chemicals salts and solvents used (LC grade) were purchased from VWR. Bidistilled water was produced in our laboratory using an Alpha-Q system (Milipore, Marlborough, Ma, USA).

\section{Microbial strains}

The yeast Exophiala spinifera (ATCC 74269) and the bacterium (ATCC 55552) patented for their ability to metabolize FB1 were purchased from ATCC (American Type Culture Collection). They were used as positive control for optimizing the conditions of in vitro FB1 degradation.

\section{Analytical procedure to assess the whole Fumonisin B1 content in high moisture maize grain} silages

To assess the whole FB1 content (expressed by the sum of free FB1 and matrix-associated FB1) in high moisture maize grain silages, we defined an analytical procedure summarized on Figure 1. 
Extraction of FB1 was performed using the protocol of Picot et al. ${ }^{5}$ with some modifications. Briefly, $5 \mathrm{~g}$ of finely ground and lyophilized maize were agitated with $25 \mathrm{~mL}$ of methanol/water $(75: 25, \mathrm{v} / \mathrm{v})$ for $15 \mathrm{~min}$. After centrifugation, filtrates were adjusted to $\mathrm{pH} 6.5$ and $5 \mathrm{~mL}$ were purified using Bond Elut Strong anion exchange (SAX) cartridges (Varian, Palo Alto, CA). Fumonisins were eluted with $10 \mathrm{~mL}$ of methanol/acetic acid $(99: 1, \mathrm{v} / \mathrm{v})$, which was evaporated to dryness under a nitrogen stream at $60{ }^{\circ} \mathrm{C}$. Dry samples were dissolved in acetonitrile/water $(50: 50, \mathrm{v} / \mathrm{v})$, filtered through a $0.22 \mu \mathrm{m}$ filter and analysed by LC-MS as described below. Extractions and analysis of free FB1 were performed in triplicate.

Matrix-associated fumonisins were extracted according to the method proposed by Dall'Asta et al. ${ }^{45}$, ${ }^{46}$ with some modifications. After extraction of free FB1, the residue of ground maize was dried overnight. Then, aliquots $(1 \mathrm{~g})$ were subjected to alkaline hydrolysis $\left(25 \mathrm{~mL} 2 \mathrm{M} \mathrm{KOH}, 25^{\circ} \mathrm{C}, 90 \mathrm{~min}\right)$ and followed by a liquid/liquid extraction with $25 \mathrm{~mL}$ acetonitrile (performed twice). The organic phases were recovered, pooled and evaporated to dryness using a rotavapor (BÜCHI Rotavapor R-200) at 25 ${ }^{\circ} \mathrm{C}$. The final precipitates were dissolved in $2 \mathrm{~mL}$ of acetonitrile/water $(50: 50, \mathrm{v} / \mathrm{v})$ and filtered through a $0.22 \mu \mathrm{m}$ filter before LC-MS analysis. Extractions and analysis of matrix-associated FB1 were performed in triplicate.

LC-MS analyses were performed using a QTrap 2000 system (Applied Biosystems, France) equipped with a TurboIon Spray ESI source and coupled to an 1100 Series HPLC system (Agilent, France). Chromatographic separation was performed on a Kinetex XB- C18 100 A column (150 x 4.6 mm, 2.6 $\mu \mathrm{m})($ Phenomenex, France). The mobile phase consisted of $0.1 \%$ formic acid in water (v/v) (solvent A) and $0.1 \%$ formic acid in methanol (v/v) (solvent $\mathrm{B}$ ) according to the following gradient: 50 to $70 \% \mathrm{~B}$ in $11 \mathrm{~min}, 70 \% \mathrm{~B}$ for $4 \mathrm{~min}, 70$ to $50 \% \mathrm{~B}$ in $1 \mathrm{~min}$ and kept at 50\% B for $7 \mathrm{~min}$ (post-run reconditioning). The flow rate was kept at $0.7 \mathrm{~mL} \cdot \mathrm{min}^{-1}$ and $0.35 \mathrm{~mL} \cdot \mathrm{min}^{-1}$ went to the electrospray source. The column temperature was $45^{\circ} \mathrm{C}$ and injection volume was $5 \mu \mathrm{L}$. LC-MS analyses were carried out using MRM monitoring mode for FB1 and HFB1 quantification. For this, monitoring of two transitions for each analyte was performed, the primary transition was used for quantification and the second transition was used for identification (Table 1). In the particular case of HFB1, to avoid misidentification because of 
the poor specificity of MRM transitions, the absence of matrix artefacts was checked in the noncontaminated silage A samples at 3 time points of fermentation. Quantification was performed by external calibrations with standard solutions of FB1 and HFB1 prepared from commercial pure solutions ranging from 1 to 5000 ng. $\mathrm{mL}^{-1}$.

\section{Isolation of FB1 degrading microorganisms}

An enrichment culture procedure based on the method proposed by Benedetti et al. ${ }^{28}$ and Shima et al. ${ }^{47}$ was implemented. A minimum medium (MM) described by Molnar et al. ${ }^{48}$ supplemented with 0.2 g.L $\mathrm{L}^{-1}$ of yeast extract (Difco ${ }^{\mathrm{TM}}$, Illkirch, France) was used leading to medium MMYE. At each time point of fermentation, aliquots of silage types $\mathrm{E}, \mathrm{F}, \mathrm{G}$ and $\mathrm{H}$ were mixed for gathering initially small populations of FB1-transforming microorganisms. Then, one $g$ of these pooled samples were suspended in $9 \mathrm{~mL}$ of dispersing solution (phosphate buffer $50 \mathrm{mM}$; $\mathrm{pH} 7.4,+0.01 \%$ Tween 80 ), vigorously shaken for $1 \mathrm{~min}$ and allowed to settle for $15 \mathrm{~min}$. Five $\mathrm{mL}$ of supernatant of this solution was collected and considered as the initial inoculum (N0). $100 \mu \mathrm{L}$ of N0 solution was used to inoculate $1 \mathrm{~mL}$ of MMYE medium supplemented with $250 \mu \mathrm{g} \cdot \mathrm{mL}^{-1}$ of FB1. Cultures were incubated at $25{ }^{\circ} \mathrm{C}$ for 8 days with shaking $\left(150 \mathrm{rpm} \cdot \mathrm{min}^{-1}\right)$ in order to obtain the N1 inoculum used to inoculate N2. Following the same procedure, successive cultures were repeated until N5. $100 \mu \mathrm{L}$ of N5 solution was diluted up to $10^{-5}$ in $900 \mu \mathrm{L}$ of dispersing solution. Finally, $100 \mu \mathrm{L}$ from each dilution was spread on MRS agar medium (De Man, Rogosa, Sharpe; Difco ${ }^{\mathrm{TM}}$, France) supplemented with Pimaricin as antifungal $\left(0.2 \mathrm{mg} . \mathrm{L}^{-1}\right)$ for selecting lactic acid bacteria, TS agar medium (Tryptic soy medium, Sigma-Aldrich, St Quentin Fallavier, France) supplemented with Pimaricin for other bacteria, and Malt extract agar medium (Difco ${ }^{\mathrm{TM}}$, Illkirch, France) supplemented with antibiotics chloramphenicol $\left(0.2 \mathrm{mg} \cdot \mathrm{L}^{-1}\right)$ and penicillin (0.02 mg. $\left.\mathrm{L}^{-1}\right)$ for selecting yeasts. Plates were inoculated in triplicate and incubated at $25^{\circ} \mathrm{C}$ for $48-96$ h. Most representative colonies appearing on plates and selected according to morphology criteria were collected and stored at $4{ }^{\circ} \mathrm{C}$.

Selection of microorganisms able to growth in a minimum medium enriched with FB1 as source of $\mathbf{C}$ and $\mathrm{N}$ 
Microbial isolates were first tested for their capacity to grow in MM supplemented with $250 \mu \mathrm{g} . \mathrm{mL}^{-}$ ${ }^{1}$ of FB1 (MM-FB1). For this, pre-cultures in rich liquid medium (MRS and TS for bacteria and Malt Extract Broth for yeast) of each isolate were used. At the log growth phase, the concentrations of broth suspensions were determined (Absorbance at $600 \mathrm{~nm}$ ) and adjusted to $1.5 \pm 0.2$ absorbance values. Aliquots of $25 \mu \mathrm{L}$ of microbial cultures were inoculated into 96-well microplates (CellStar, Greiner BioOne) containing MM-FB1 medium (200 $\mu \mathrm{L}$ per well) and incubated at $25{ }^{\circ} \mathrm{C}$ for $48 \mathrm{~h}$. Absorbance values $(600 \mathrm{~nm})$ were measured each hour by spectrophotometry (TECAN, InfiniteM200 Pro) after horizontal shaking for $30 \mathrm{~s}$. Four measures at four different points within each well were performed. Cultures of ATCC 74269 and ATCC 55552 known for their ability to degrade the FB1 were considered as positive controls and cultures without toxin (MM) were considered as negative ones. Assays and controls were performed in five replicates. Positive isolates were selected by comparing their growth curves in MM-FB1 and in MM. The significance of the differences observed between assays and controls was determined at 1 to 3 time-points. Finally, these candidate isolates were collected and stored at $4{ }^{\circ} \mathrm{C}$ and in liquid nitrogen (containing $30 \%$ glycerol).

\section{Selection of microorganisms able to degrade FB1 in vitro}

To confirm the capacity of candidate microorganisms to metabolize FB1, a test similar to the one proposed by Niderkorn et al. ${ }^{49}$ was performed. Culture conditions were firstly defined (e.g. culture media, FB1 content, incubation time) using the two reference microorganisms (ATCC 74269 and ATCC 55552). Therefore, $200 \mu \mathrm{L}$ of microbial culture at log phase of growth ( $24 \mathrm{~h}$ or $48 \mathrm{~h}$ culture in a rich medium) was inoculated into Erlenmeyer flasks containing $90 \mathrm{~mL}$ of liquid medium: MRS for lactic acid bacteria, TS broth for bacteria and Malt Extract broth for yeast. These cultures were incubated at $25^{\circ} \mathrm{C}$ (yeast) and $30{ }^{\circ} \mathrm{C}$ (bacteria) for $48 \mathrm{~h}$ with shaking. Then, the cultures were centrifuged $(3000 \mathrm{~g}$, $10 \mathrm{~min}, 5^{\circ} \mathrm{C}$ ) and the supernatants were discarded. Microbial pellets were washed three times with a phosphate buffer (10 mM, pH 7.4). These pellets were suspended in $2 \mathrm{~mL}$ (bacteria) or $5 \mathrm{~mL}$ (yeast) of rich culture media containing FB1 $\left(5 \mu \mathrm{g} \cdot \mathrm{mL}^{-1}\right)$ and incubated at $25{ }^{\circ} \mathrm{C}$ for $96 \mathrm{~h}$ with shaking. Positive controls (ATCC strain cultures) and negative controls (microorganisms in culture media without FB1 and un-inoculated medium with FB1) were included. Finally, cultures were analysed at $0 \mathrm{~h}$ and after 96 
$\mathrm{h}$ of incubation. They were centrifuged $\left(3000 \mathrm{~g}, 10 \mathrm{~min}, 5{ }^{\circ} \mathrm{C}\right)$, supernatants were filtered $(0.22 \mu \mathrm{m}$, Merck millipore) and stored at $-20{ }^{\circ} \mathrm{C}$ for FB1 and HFB1 analysis by LC-MS/MS. The experiment was performed in triplicate.

\section{LC-MS analysis of microbial cultures}

Microbial supernatants were analysed by LC-MS using the same equipment and conditions described for silage samples with some modifications. Briefly, the mobile phase consisted of $0.1 \%$ formic acid in water (v/v) (solvent A) and $0.1 \%$ formic acid in methanol/acetonitrile (50/50 v/v) (solvent B) according to the following gradient: 45 to $80 \% \mathrm{~B}$ in $11 \mathrm{~min}, 80 \% \mathrm{~B}$ for $4 \mathrm{~min}, 80$ to $45 \% \mathrm{~B}$ in $1 \mathrm{~min}$ and kept at 45\% B for 5 min (post-run reconditioning). These modifications entailed retention time values of 5.3 and $3.7 \mathrm{~min}$ for FB1 $(\mathrm{m} / \mathrm{z}, 722)$ and HFB1 $(\mathrm{m} / \mathrm{z}, 406)$, respectively.

\section{DNA extraction and taxonomic identification of candidate microorganisms}

After lyophilisation (Flexi-Dry; Oerlikon Leybold, Germany), DNA of pure isolates was extracted using the Nucleon Phytopure kit according to the manufacturer's instructions (Amersham, Toulouse, France). Quality of each DNA sample was determined using a spectrophotometer (Nanodrop Technology, Cambridge, UK) and verified by gel electrophoresis (agarose 1\%, Eurobio, Courtaboeuf, France).

The primers used for amplifying and sequencing the D1/D2 region of 26S rDNA in yeasts were: NL1 (5'-GCA TAT CAA TAA GCG GAG GAA-3') and NL4 (5' GGT CCG TGT TTC AAG ACG G-3') described by Kurtzman and Robnett ${ }^{50}$ and the primers for the V3-V4 region of $16 \mathrm{~S}$ rDNA in bacteria were: V3 (5' ACT CCT ACG GGA GGC AGC AG-3') and V4 (5' TAC NVG GGT ATC TAA TCC) described by Cai et al. ${ }^{51}$ PCR was carried out in a $25 \mu \mathrm{L}$ reaction mix (GoTaq ${ }^{\circledR}$ reaction buffer $1 \mathrm{X}, 2.5$ $\mathrm{mM}$ of $\mathrm{MgCl}_{2}, 0.1 \mathrm{mM}$ dNTPs, $0.02 \mathrm{U} \cdot \mu \mathrm{L}^{-1}$ of DNA Polymerase and $0.1 \mathrm{mM}$ of forward and reverse specific primer) with 35 cycles that consisted of $94{ }^{\circ} \mathrm{C}$ for $60 \mathrm{~s}, 55{ }^{\circ} \mathrm{C}$ for $90 \mathrm{~s}, 72{ }^{\circ} \mathrm{C}$ for $90 \mathrm{~s}$. The reaction was completed by a final elongation step at $72{ }^{\circ} \mathrm{C}$ for $5 \mathrm{~min}$. The PCR products were verified by gel electrophoresis (agarose 1\%) and paired-end sequenced (Beckman Coulter Genomics, Paris, 
France). Finally, the generated DNA sequences were aligned using the Bioedit program ${ }^{52}$ and compared against NCBI database using BLAST..$^{53}$

\section{Statistical analyses}

Results of free FB1 and matrix-associated FB1 concentration in HMMG silage were reported as mean concentration values $( \pm \mathrm{SD})$ of three analytical repetitions corresponding to three extractions per sample. Differences between three fermentation time points for each silage type were determined with multiple comparisons test (ANOVA) using the Duncan method (XLStat, v2014.6.03 AddinSoft, France). Levels of significance were set at $\alpha=0.05$.

Concerning the comparison in microbial growth kinetics between isolates with FB1 and negative controls (without FB1), significances of the differences in means of absorbance values for 5 replications at selected time points were evaluated with the t-student test. Levels of significance were set at $\alpha=0.05$

\section{RESULTS AND DISCUSSIONS}

\section{Fate of FB1 during HMMG ensiling process}

To monitor the ensiling process in our experimental devices, $\mathrm{pH}$ and moisture content were measured during fermentation. In overall, the mini-silos gave rise to homogeneous fermentation processes with a continuous decrease of $\mathrm{pH}$ values from 5.7-6.3 before ensiling to 4.0-4.6 at day 141. In addition, the percentage of moisture contents ranged from $32 \%$ to $36 \%$ during the ensiling process without significant changes. These values were consistent with those currently observed in farm silages. ${ }^{36,54}$ At opening of the mini-silos, none of the silages were colonized by rots and they all had a pleasant smell. Therefore, these results suggested a well-conducted ensiling process in our experimental mini-silos.

It has been extensively showed that the use of conventional methods for FB1 determination in maize and maize-based products do not allow assessing the matrix associated FB1 which are not solubilized with the solvent-based extraction procedure. ${ }^{18}$ Since fermentation during HMMG silages could lead to physicochemical changes in the maize matrix and to the development of microorganisms that can favour 
the sequestration of mycotoxins and result in a significant underestimation of FB1 content, we assessed the whole content of FB1 that includes both free and matrix-associated forms using the procedure described in Figure 1.

Free FB1 evolution in HMMG silage

According to literature data, the evolution of FB1 during the maize ensiling process has been yet only addressed in whole plant maize silages. ${ }^{6,39-41,55}$ In this work, we examined for the first time, the fate of FB1 during ensiling of HMMG (Figure 2). At day 0, three of the four maize grain silages showed high levels of toxin, with contamination values ranging from 7 to $11.9 \mu \mathrm{g} . \mathrm{g}^{-1}$ of maize. As expected, silage A, which was initially prepared with grains from non-contaminated plants, exhibited a low level of FB1, close to $0.2 \mu \mathrm{g} \cdot \mathrm{g}^{-1}$. Contaminated silages B, C and D showed a significant decrease in free FB1 concentration after 78 days of ensiling. The decrease during the following 63 days was not significant. The rates of decrease in free FB1 concentrations after four months of fermentation were different, depending on the considered silage. During fermentation of silage B, a drastic decrease of free FB1 content was observed, reaching up to $93 \%$ after 141 days. The percentage of free FB1 loss at the end of the process reached $41 \%$ and $38 \%$ for silage $\mathrm{D}$ and $\mathrm{C}$, respectively. The same experiment was repeated with maize grains harvested in 2013 from four different fields showing symptoms of Fusarium ear rot. The main results obtained with harvest 2013 mini-silos are summarized on Table 2. In overall, it supports the occurrence of situations conducive to a consequent reduction of free FB1 during fermentation. The percentage of free FB1 loss ranged between $54.1 \%$ for silage F and $76.3 \%$ for silage H. The observed decrease in free FB1 was consistent with data reported by Keller et al. ${ }^{6}$ and Boudra et al. ${ }^{39}$ that highlighted a significant decrease in free FB1 concentrations reaching as much as $90 \%$ in three month-old whole plant silages. Such a decrease was however not evidenced by Uegaki et al. ${ }^{40}$ and Latorre et al. ${ }^{41}$ who indicated stable free FB1 concentrations in whole plant silages, even after eight months of storage. As corroborated by numerous publications, one of the main processes that could explain the free FB1 decrease results from adsorption mechanisms. ${ }^{14}$ 16, 56 Fumonisin adsorption mechanisms which generate FB1 complexed forms may take place during silage fermentation with the matrix or fermentative bacterial peptidoglycans. ${ }^{56}$ Association with the matrix can involve either 
covalent and noncovalent interactions between the FB1 tricarballylic moieties and hydroxyl groups of maize carbohydrates or amino-acids, esterification with fatty acids, or physical entrapment of FB1 in maize macromolecules such as starch and proteins. ${ }^{17,57-59}$

\section{Matrix-associated FB1 evolution in HMMG silage}

Procedures based on an alkaline hydrolysis step have been proposed by several authors to estimate matrix-associated FB1 forms. ${ }^{41,45,46,59-61}$ According to Bryła et al. ${ }^{59}$ this alkaline hydrolysis produces a disruption of the primary and secondary structure of maize macromolecules involved in the toxin complexation and the release of the sequestered toxin, together with a cleavage of the FB1 side chains and elimination of carboxylic groups that are potential sites of covalent modification. Therefore, the cleavage of FB1 side chains after alkaline hydrolysis gives rise to the measurable HFB1 metabolite. Such alkaline hydrolysis based procedure was applied to evaluate and follow the concentrations of matrix-associated FB1 in the different HMMG silages considered in our study. As reported on Figure 3, significant amounts of matrix-associated FB1 were detected for any of the considered silages and any of the fermentation times. At day 0 before the ensiling process, the estimated amounts of matrixassociated FB1 ranged between $4 \mu \mathrm{g} . \mathrm{g}^{-1}$ for silage $\mathrm{D}$ and $6.3 \mu \mathrm{g} \cdot \mathrm{g}^{-1}$ for silage $\mathrm{B}$. When compared to total FB1 levels (free FB1 + matrix-associated FB1), the amounts of matrix-associated FB1 accounted for 26\% in silage D and 40\% in silages B and C. Similarly, in 2013 harvest mini-silos, matrix-associated FB1 forms reached between 5 to 30\% (Table 2). These results were similar to previous reports ${ }^{41,61}$ addressing whole plant maize silages and raw maize. In addition, the ratios of matrix-associated FB1 to free FB1 determined in 2011 and 2013 silages varied from 0.05 to 0.7 in contaminated non-fermented maize grains and never reached values higher than one as observed by Bryła et al. ${ }^{59}$. Indeed, the matrixassociated to free FB1 ratios determined by the former authors in different maize based-food products including noodles, corn flakes and maize snacks ranged between 1.47 and 5.95. During the ensiling process of 2011 silages, the concentrations of matrix-associated FB1 decreased weakly, a decrease that was however not statistically significant. At day 141, matrix-associated FB1 loss attained $2.7 \mu \mathrm{g} . \mathrm{g}^{-1}$ and $1.8 \mu \mathrm{g} \cdot \mathrm{g}^{-1}$ of maize for silage B and D, respectively. Additionally as reported in Table 2, data on the evolution of matrix-associated FB1 in two of the 2013 silages (E and G) support the results obtained 
with 2011 silages, suggesting that the fermentation process did not favour the sequestration of FB1 within the maize grain matrix. Opposite results were obtained with silages $\mathrm{F}$ and $\mathrm{H}$ that showed a weak increase in matrix-associated FB1 concentration after 141 days of fermentation $\left(0.54 \mu \mathrm{g} \cdot \mathrm{g}^{-1}\right.$ of maize for silage $\mathrm{F}$ and $1.26 \mu \mathrm{g} \cdot \mathrm{g}^{-1}$ for silage $\mathrm{H}$ ). Nonetheless this event clearly did not wholly explain the decrease in free FB1 concentration (8.8 and $7.5 \mu \mathrm{g} \cdot \mathrm{g}^{-1}$ of maize for silages $\mathrm{F}$ and $\mathrm{H}$, respectively).

Taken together, our results on free and matrix-associated FB1 contents in mini-silos prepared with two cropping year harvests indicated a significant decrease in total FB1 contents during HMMG ensiling process. This reduction was at least partly ascribed to a mechanism different from FB1 adsorption, since matrix-associated FB1 quantities exhibited relatively stable levels during fermentation. We therefore hypothesized that the FB1 decrease observed in this work could be the result of biodegradation mechanisms involving endogenous microbial activities. The microbiota composing HMMG mini-silos contaminated with FB1 could therefore contain microorganisms able to degrade the toxin, either individually or in cooperation within the microbiota. The detection of degradation metabolites of FB1 in the silages would have been an argument supporting a biodegradation mechanism. Nonetheless whatever the considered silage and day of fermentation, the occurrence of free HFB1 was never highlighted in the LC-MS chromatograms. Microorganisms in the silages were probably able to transform HFB1 in more degraded metabolites. The lack of this molecule was also reported by Latorre et al. ${ }^{41}$ for whole plant silages

\section{Search of microbial agents associated with FB1 degradation in high moisture maize grain silages}

To assess the hypothesis that the measured FB1 disappearance in HMMG silages resulted from microbial degradation activities, a culture-dependent approach using mini-silos E, F, G and $\mathrm{H}$ at four time points of fermentation was implemented.

Isolation of microorganisms able to grow in a minimal medium supplemented with FB1

By using optimized culture screening methods, several mycotoxin degrading microorganisms have been isolated from complex environments. ${ }^{22,}$ 23, 28, 47, 48, 62-67 Among these culture methods, enrichment procedures based on successive culture cycles in presence of mycotoxins were shown to notably favour 
an initially small population of mycotoxin-transforming microorganisms to become the majority population and to increase the probability of isolating cultivable active strains. ${ }^{47}$ This culture strategy was therefore applied. After five enrichment cycles for each time point of fermentation, we obtained 98 isolates of bacteria and yeasts from which 37 were selected based on morphological criteria and their optimal viability in in vitro cultures.

These 37 isolates were assessed for their ability to growth in a minimal broth (MM) supplemented with FB1 as the sole carbon and nitrogen source. Positive isolates were selected by comparing microbial growth curves (absorbance at $600 \mathrm{~nm}$ ) of cultures enriched or not with FB1 for $48 \mathrm{~h}$ of incubation. Typical microbial growth kinetics are reported on Figure 4. Figure 4A and 4B show two curves corresponding to microbial isolates we considered as positive and interesting to further characterize, where the presence of FB1 seems to favour a higher growth ( $p \leq 0.05$ for both isolates at 28 hours). Figures 4C and 4D described typical curves obtained with negative isolates where the presence of FB1 did not significantly modify the growth pattern (Figure 4C) or was even deleterious (Figure 4D). This analysis allowed identifying 9 positive isolates, 5 bacteria and 4 yeasts, gathered in Table 3 . It is noteworthy that $24 \%$ of the tested isolates appeared as potential FB1 degraders in this experiment. Both the enrichment procedure and the quality of the matrix used proved to be favorable for this selection. These data corroborate the conclusion of $\mathrm{McCormick}^{21}$ who indicated that microorganisms able to growth in limited conditions are logically expected to metabolize the toxin.

The sequence analysis of partial 16S rRNA ( $465 \mathrm{bp}$, for bacteria) and 26S rRNA ( $550 \mathrm{bp}$, for yeasts) genes of these nine positive isolates revealed, with $100 \%$ sequence similarities (Table 3), that they belonged to two yeast species: Pichia fermentans (isolate N183), Candida glabrata (isolates N345, N346 and N353) and four bacteria species: Lactobacillus brevis (isolate N195 and N197), Klebsiella oxytoca (isolate N186), Klebsiella variicola (isolate VA26), Bacillus sp. (isolate N339). Most of these strains belong to species or genus that have already been reported for their occurrence in maize grains or fermentative processes such as silages. Pichia fermentans has been reported to occur at relatively high frequency, both in fresh and ensiled maize. ${ }^{68}$ Candida spp. was also detected in HMMG silages. ${ }^{36}$ However, the species $C$. glabrata is a prevalent yeast pathogen in humans ${ }^{69}$ which implies that if 
promising properties of $C$. glabrata isolates are confirmed, their usage safety has to be rigorously studied..$^{70}$ Klebsiella oxytoca, a facultative anaerobic enterobacteria, is ubiquitous and involved in plant microbiota as one of the nitrogen-fixing microorganisms. ${ }^{71,72}$ It has been found in both fresh maize forage and throughout the whole fermentative process in silage samples evaluated by Santos et al. ${ }^{73}$ Klebsiella variicola is an endophyte isolated from many plants ${ }^{74}$ and was identified as a component of endophytic bacterial communities in seeds of maize. ${ }^{43}$ Lactobacillus brevis (belonging to lactic acid bacteria, LAB) is known for its capacity to colonize maize silage and its essential role during the fermentation process. ${ }^{75} \mathrm{LAB}$ are interesting candidates as mycotoxin detoxifying agents because of their easy adaptation and ability to grow in the particular fermentative ecosystems. ${ }^{76}$ Finally, Bacillus spp. strains have been frequently isolated from maize and whole plant maize silage. ${ }^{44}, 62$ Despite the absence of original species in our isolates, we should have selected strains with enhanced specific properties for FB1 transformation.

In vitro FB1 biodegradation by HMMG microorganisms

To confirm and characterize the capacity of the nine candidate microorganisms to degrade FB1, both FB1 and HFB1 amounts were evaluated in broth cultures before and after four days of incubation (Table 3). As shown by reference microbial strains (ATCC 74269 and ATCC 55552), the experimental conditions used in this work were efficient for revealing decreases of FB1 contents and the production of HFB1 in culture broths. The ability to decrease FB1 levels in culture medium was confirmed for all candidate microorganisms, with an efficiency ranging from $6 \%$ to $33 \%$ which was lower than those reported by reference microbial strains in the given conditions of our test. The highest percentages of FB1 loss were emphasized for two isolates: L. brevis N195 and L. brevis N197. Similar percentages of FB1 decrease were reported by Camilo et al. ${ }^{62}$ and Mokoena et al ${ }^{77}$ for a mixed culture of Lactobacillus delbrueckii and Streptococcus lactis and several Bacillus sp. strains.

To ensure that the observed FB1 decrease was the result of a degradation process and not only of adsorption events, the occurrence of FB1 metabolites such as HFB1 was investigated. HFB1 is a hydrolyzed form of FB1 that lacks the two TCA moieties. Quantifiable levels of HFB1 were only observed in the culture media where the highest decreases in FB1 were highlighted: L. brevis N195 and 
L. brevis N197. These data undoubtedly corroborate that the two former microorganisms have the enzymatic capacity to metabolize FB1. The best efficiency for degrading FB1 observed in the in vitro test (Table 3) was close to $33 \%$ (L. brevis N195) while more than $90 \%$ of FB1 degradation was observed in some silages such as silage B (Figure 2). These data can suggest that the corn grain maize matrix is more conducive to the expression of enzymatic activities involved in FB1 degradation compared to the culture medium we used for the in vitro test. Besides it is highly likely that the significant degradation of FB1 in silages results from microbial interactions leading to a cooperative mechanism, i.e. enzymes involved in the mycotoxin degradation are induced by metabolites produced by another microorganism. ${ }^{20}$ As it clearly appears in table 3 , the apparent percentages of conversion of FB1 into HFB1 were low (up to 17\%), when compared to cultures of references microorganisms known as FB1 degrading strains (Table 3). Three main rationales could explain these low percentages. First, it could be not excluded that adsorption and degradation mechanisms concomitantly occurred in the liquid media and that, consequently, the observed decrease in FB1 can only be partially ascribed to a degradation activity. Further analyses will allow determining the part of FB1 binding with microbial cell wall components. Secondly, the FB1 degradation pathway can have stopped before the synthesis of HFB1. Indeed, Fodor et al. ${ }^{78}$ reported a mixed microbial culture composed of Escherichia coli and Bacteroides spp. that was able to transform in vitro $49 \%$ of FB1 and was also characterized by a low percentage of FB1 conversion into HFB1 (less than 1\%). They ascribed this low percentage to the accumulation of a partially hydrolysed metabolite called pHFB1 which corresponds to FB1 minus one TCA moiety. Therefore, since partially hydrolysed metabolites as pHFB1 can be produced by microbial activities as a first step of degradation, further search on these metabolites in microbial cultures will be necessary. Finally, further transformations of HFB1 into more degraded compounds could have occurred in our liquid media. This hypothesis was raised up by Benedetti et al. ${ }^{28}$ who reported the degradation of FB1 into heptadecanone, isononadecene, octadecenal and eicosane caused by a bacterium related to the Delftia/Comamonas group. Moreover, several microorganisms have been reported for their capacity to completely metabolize FB1. ${ }^{22-24,27,30,31,79}$ As described by several authors, the complete degradation of the toxin involves two consecutive microbial activities: decarboxylation and deamination. ${ }^{21,24,26}$ 


\section{CONCLUSION}

Using in vitro simulated silage models prepared with FB1 naturally contaminated grains from two cropping years; we evidenced for the first time the decrease of FB1 content during HMMG ensiling process. This decrease was explained by microbial degradation activities rather than matrix-association mechanisms. Nine FB1-degrading microorganisms were isolated from this matrix. Notably, two bacterial isolates, L. brevis $\mathrm{N} 195$ and L. brevis N197, were emphasized for their capacity to metabolize FB1 in vitro. Additional studies will be required to fully characterize their kinetic of FB1 degradation in vitro and within maize-based products and to identify both the enzymatic pathways and the genes involved in this microbial activity. Since microbial degradation of mycotoxins represents an environmental friendly decontamination option and an irreversible mechanism, maize grains and HMMG silages are a promising reservoir of new FB1 degrading microorganisms that could be used individually, or in mixed cultures, for post-harvest remediation of FB1-contaminated commodities in biological processes applied before consumption of maize grains by livestock or humans.

\section{ACKNOWLEDGMENTS}

This work was supported by Lallemand Animal Nutrition and the French Ministère de 1'Enseignement Supérieur et de la Recherche as a PhD grant. The authors thank Christian Barreau, Frédérique Chaucheyras, Mathieu Castex and Pascal Drouin, for their scientific support during this work.

\section{REFERENCES}

1. Garcia S and Heredia N, Mycotoxins in Mexico: epidemiology, management, and control strategies. Mycopathologia 162:255-264 (2006). 
2. Stockmann-Juvala $\mathrm{H}$ and Savolainen $\mathrm{K}, \mathrm{A}$ review of the toxic effects and mechanisms of action of fumonisin B1. Hum Exp Toxicol 27:799-809 (2008).

3. González Pereyra ML, Pereyra CM, Ramírez ML, Rosa CAR, Dalcero AM and Cavaglieri LR, Determination of mycobiota and mycotoxins in pig feed in central Argentina. Lett ApplMicrobiol 46:555-561 (2008).

4. Marasas WFO, Fumonisins: their implications for human and animal health. Nat Toxins 3:193198 (1995).

5. Picot A, Barreau C, Pinson-Gadais L, Piraux F, Caron D, Lannou C and Richard-Forget F, The dent stage of maize kernels is the most conducive for fumonisin biosynthesis under field conditions. Appl Environ Microbiol 77:8382-8390 (2011).

6. Keller LAM, González Pereyra ML, Keller KM, Alonso VA, Oliveira AA, Almeida TX, Barbosa TS, Nunes LMT, Cavaglieri LR and Rosa CAR, Fungal and mycotoxins contamination in corn silage: Monitoring risk before and after fermentation. J Stored Prod Res 52:42-47 (2013).

7. Alonso VA, Pereyra CM, Keller LA, Dalcero AM, Rosa CA, Chiacchiera SM and Cavaglieri LR, Fungi and mycotoxins in silage: an overview. J Appl Microbiol 115:637-643 (2013).

8. European Commission. Commission Regulation (EC) No 466/2001 of 8 March 2001, Setting maximum levels for certain contaminants in foodstuffs. Off. J Eur Comm L 077: 1-13 (2001).

9. He J and Zhou T, Patented techniques for detoxification of mycotoxins in feeds and food matrices. Recent Pat Food Nutr Agric 2:96-104 (2010).

10. Jard G, Liboz T, Mathieu F, Guyonvarc'h A and Lebrihi A, Review of mycotoxin reduction in food and feed: from prevention in the field to detoxification by adsorption or transformation. Food Addit Contam Part A Chem Anal Control Expo Risk Assess28:1590-1609 (2011).

11. Kolosova A and Stroka J, Substances for reduction of the contamination of feed by mycotoxins: a review. World Mycotoxin J 4:225-256 (2011). 
12. Alberts JF, van Zyl WH and Gelderblom WCA, Biologically Based Methods for Control of Fumonisin-Producing Fusarium Species and Reduction of the Fumonisins. Front Microbiol 7:548 (2016).

13. Štyriak I, Conková E, Kmec V, Böhm J and Razzazi E, The use of yeast for microbial degradation of some selected mycotoxins. Mycotoxin Res 17:24-27 (2001).

14. Niderkorn V, Boudra $\mathrm{H}$ and Morgavi Dp, Binding of Fusarium mycotoxins by fermentative bacteria in vitro. J Appl Microbiol 101:849-856 (2006).

15. Dalié DKD, Deschamps AM and Richard-Forget F, Lactic acid bacteria - Potential for control of mould growth and mycotoxins: A review. Food Control 21:370-380 (2010).

16. Dalié D, Pinson-Gadais L, Atanasova-Penichon V, Marchegay G, Barreau C, Deschamps A and Richard-Forget F, Impact of Pediococcus pentosaceus strain L006 and its metabolites on fumonisin biosynthesis by Fusarium verticillioides. Food Control 23:405-411 (2012).

17. Berthiller F, Crews C, Dall'asta C, Saeger SD, Haesaert G, Karlovsky P, Oswald IP, Seefelder W, Speijers G and Stroka J, Masked mycotoxins: A review. Mol Nutr Food Res 57(1):165-186(2013).

18. Rychlik M, Humpf H-U, Marko D, Dänicke S, Mally A, Berthiller F, Klaffke H and Lorenz N, Proposal of a comprehensive definition of modified and other forms of mycotoxins including "masked" mycotoxins. Mycotoxin Res 30:197-205 (2014).

19. De Mil T, Devreese M, De Baere S, Van Ranst E, Eeckhout M, De Backer P and Croubels S, Characterization of 27 Mycotoxin Binders and the Relation with in Vitro Zearalenone Adsorption at a Single Concentration. Toxins 7:21-33 (2015).

20. Karlovsky P, Biological detoxification of fungal toxins and its use in plant breeding, feed and food production. Nat Toxins 7:1-23 (1999).

21. McCormick SP, Microbial detoxification of mycotoxins. J Chem Ecol 39:907-918 (2013).

22. Duvick J, Rood T, Maddox J and Gilliam J, Detoxification of Mycotoxins In Planta as a Strategy for Improving Grain Quality and Disease Resistance: Identification of Fumonisin-Degrading Microbes 
from Maize, in Molecular Genetics of Host-Specific Toxins in Plant Disease, ed. by Kohmoto K and Yoder O. Springer Netherlands, pp 369-381 (1998).

23. Duvick J, Rood T and Wang X, Fumonisin detoxification enzymes, US Patent 5716820 (1998).

24. Blackwell BA, Gilliam JT, Savard ME, David Miller J and Duvick JP, Oxidative deamination of hydrolyzed fumonisin B(1) (AP(1)) by cultures of Exophiala spinifera. Nat Toxins 7:31-38 (1999).

25. Duvick J, Maddox J and Gilliam J, Composition and Methods for Fumonisin Detoxification. US Patent 6538177 (2003).

26. Vanhoutte I, Audenaert K and De Gelder L, Biodegradation of Mycotoxins: Tales from Known and Unexplored Worlds. Front Microbiol 7:561 (2016).

27. Täubel $M$, Isolierung und Charakterisierung von Mikroorganismen zur biologischen Inaktivierung von Fumonisinen. Doctoral thesis, University of Natural Resources and Applied Life Sciences, Vienna Austria (2005).

28. Benedetti R, Nazzi F, Locci R and Firrao G, Degradation of Fumonisin B1 by a Bacterial Strain Isolated from Soil. Biodegradation 17:31-38 (2006).

29. Grenier B, Bracarense AP, Schwartz HE, Trumel C, Cossalter AM, Schatzmayr G, Kolf-Clauw M, Moll WD and Oswald IP, The low intestinal and hepatic toxicity of hydrolyzed fumonisin B(1) correlates with its inability to alter the metabolism of sphingolipids. Biochem Pharmacol 83:1465-1473 (2012).

30. Chatterjee R, Duvick JP and English J, AP1 amine oxidase variants, EP Patent 2275536 A1 (2011).

31. Heinl S, Hartinger D, Thamhesl M, Vekiru E, Krska R, Schatzmayr G, Moll WD and Grabherr R, Degradation of fumonisin B-1 by the consecutive action of two bacterial enzymes. I Biotechnol 145:120-129 (2010).

31. Heinl S, Hartinger D, Thamhesl M, Schatzmayr G, Moll W-D and Grabherr R, An aminotransferase from bacterium ATCC 55552 deaminates hydrolyzed fumonisin $\mathrm{B}_{1}$. Biodegradation 22:25-30 (2011). 
33. Zhao L, Weiner DP and Hickle L, Transaminases, deaminases and aminomutases and compositions and methods for enzymatic detoxification, WO Patent 2004085624 A2 (2004).

34. Moll WD, Hartinger D, Grießler K, Binder EM and Schatzmayr G, Method for the production of an additive for the enzymatic decomposition of mycotoxins, additive, and use thereof, US Patent 8703460 B2(2014).

35. Hartinger D and Moll W, Fumonisin elimination and prospects for detoxification by enzymatic transformation. World Mycotoxin J 4:271-283 (2011).

36. Santos $M$, Identification and characterization of yeasts from high moisture corn and corn silages and their potential impact on in vitro rumen fermentation. Doctoral thesis, University of Delaware, Newark USA (2011).

37. Canizares GIL, Gonçalves HC, Costa C, Rodrigues L, Menezes JJL, Gomes HFB, Marques RO and Branco RH, Use of high moisture corn silage replacing dry corn on intake, apparent digestibility, production and composition of milk of dairy goats. Revista Brasileira de Zootecnia 40:860-865 (2011). 38. Persichetti Júnior P, Almeida Júnior GA, Costa C, Meirelles PRL, Silveira JPF, Panichi A, Silva MGB, Factori MA, Cavasano FA and Mendonça SA, Nutritional value of high moisture corn silage in the diet of Holstein cows. Arquivo Brasileiro de Medicina Veterinária e Zootecnia 66:1495-1503 (2014).

39. Boudra $\mathrm{H}$ and Morgavi DP, Reduction in fusarium toxin levels in corn silage with low dry matter and storage time. J Agric Food Chem 56:4523-4528 (2008).

40. Uegaki R, Tsukiboshi $T$ and Tohno $M$, Changes in the concentrations of fumonisin, deoxynivalenol and zearalenone in corn silage during ensilage. Anim Sci J 84:656-662 (2013).

41. Latorre A, Dagnac $\mathrm{T}$, Lorenzo BF and Llompart $\mathrm{M}$, Occurrence and stability of masked fumonisins in corn silage samples. Food Chem 189:38-44 (2015).

42. Barret $M$, Briand $M$, Bonneau S, Préveaux $A$, Valière $S$, Bouchez $O$, Hunault $G$, Simoneau $P$ and Jacques M-A, Emergence Shapes the Structure of the Seed Microbiota. App/ Environ Microbio/ 81:12571266 (2015). 
43. Liu Y, Zuo S, Xu L, Zou Y and Song W, Study on diversity of endophytic bacterial communities in seeds of hybrid maize and their parental lines. ArchMicrobiol 194:1001-1012 (2012).

44. Orole $\mathrm{OO}$ and Adejumo TO, Bacterial and fungal endophytes associated with grains and roots of maize. J Ecol Nat Environ 3:298-303 (2011).

45. Dall'Asta C, Galaverna G, Aureli G, Dossena A and Marchelli R, A LC/MS/MS method for the simultaneous quantification of free and masked fumonisins in maize and maize-based products. World Mycotoxin J 1:237-246 (2008).

46. Dall'Asta C, Falavigna C, Galaverna G, Dossena A and Marchelli R, In Vitro Digestion Assay for Determination of Hidden Fumonisins in Maize. J Agric Food Chem 58:12042-12047 (2010).

47. Shima J, Takase S, Takahashi Y, Iwai Y, Fujimoto H, Yamazaki M and Ochi K, Novel detoxification of the trichothecene mycotoxin deoxynivalenol by a soil bacterium isolated by enrichment culture. Appl Environ Microbiol 63:3825-3830 (1997).

48. Molnar O, Schatzmayr G, Fuchs E and Prillinger H, Trichosporon mycotoxinivorans sp. nov., a new yeast species useful in biological detoxification of various mycotoxins. Syst Appl Microbio/ 27:661671 (2004).

49. Niderkorn V, Morgavi DP, Pujos E, Tissandier A and Boudra H, Screening of fermentative bacteria for their ability to bind and biotransform deoxynivalenol, zearalenone and fumonisins in an in vitro simulated corn silage model. Food Addit Contam 24:406-415 (2007).

50. Kurtzman $\mathrm{CP}$ and Robnett $\mathrm{CJ}$, Identification and phylogeny of ascomycetous yeasts from analysis of nuclear large subunit (26S) ribosomal DNA partial sequences. Antonie van Leeuwenhoek 73:331-371 (1998).

51. Cai L, Ye L, Tong AHY, Lok S and Zhang T, Biased Diversity Metrics Revealed by Bacterial 16S Pyrotags Derived from Different Primer Sets. PLoS One 8:e53649 (2013).

52. Hall TA, BioEdit: a user-friendly biological sequence alignment editor and analysis program for Windows 95/98/NT. Nucleic Acids Symposium Series 41:95-98 (1999). 
53. Altschul SF, Gish W, Miller W, Myers EW and Lipman DJ, Basic local alignment search tool. J Mol Biol 215 (1990).

54. Danel J, Conservation du maïs humide par inertage. Evolution au cours du stockage. La lettre d'information d'ARVALIS -Institut du végétal pour la filière Alimentation Animale 33 :1(2013).

55. Gonzalez Pereyra ML, Alonso VA, Sager R, Morlaco MB, Magnoli CE, Astoreca AL, Rosa CA, Chiacchiera SM, Dalcero AM and Cavaglieri LR, Fungi and selected mycotoxins from pre- and postfermented corn silage. J Appl Microbiol 104:1034-1041 (2008).

56. Niderkorn V, Morgavi DP, Aboab B, Lemaire $\mathrm{M}$ and Boudra $\mathrm{H}$, Cell wall component and mycotoxin moieties involved in the binding of fumonisin B1 and B2 by lactic acid bacteria. J Appl Microbiol 106:977-985 (2009).

57. Seefelder W, Knecht A and Humpf HU, Bound fumonisin B1: analysis of fumonisin-B1 glyco and amino acid conjugates by liquid chromatography-electrospray ionization-tandem mass spectrometry. J Agric Food Chem 51:5567-5573 (2003).

58. Park JW, Scott * PM, Lau BPY and Lewis DA, Analysis of heat-processed corn foods for fumonisins and bound fumonisins. Food AdditContam 21:1168-1178 (2004).

59. Bryła M, Roszko M, Szymczyk K, Jędrzejczak R and Obiedziński MW, Fumonisins and their masked forms in maize products. Food Control 59:619-627 (2016).

60. De Girolamo A, Lattanzio VMT, Schena $R$, Visconti $A$ and Pascale $M$, Use of liquid chromatography-high-resolution mass spectrometry for isolation and characterization of hydrolyzed fumonisins and relevant analysis in maize-based products. J Mass Spectrom 49:297-305 (2014).

61. Oliveira MS, Diel ACL, Rauber RH, Fontoura FP, Mallmann A, Dilkin P and Mallmann CA, Free and hidden fumonisins in Brazilian raw maize samples. Food Control 53:217-221 (2015).

62. Camilo SB, Ono CJ, Ueno $\mathrm{Y}$ and Hirooka $\mathrm{EY}$, Anti-Fusarium moniliforme activity and fumonisin biodegradation by corn and silage microflora. Brazilian Arch Biol Technol 43:159-164 (2000). 
63. Fuchs E, Binder EM, Heidler D and Krska R, Structural characterization of metabolites after the microbial degradation of type A trichothecenes by the bacterial strain BBSH 797. Food Addit Contam 19:379-386 (2002).

64. Hormisch D, Hormisch D, Brost I, Kohring GW, Giffhorn F, Kroppenstedt RM, Stackebradt E, Färber P and Holzapfel WH, Mycobacterium fluoranthenivorans sp. nov., a Fluoranthene and Aflatoxin B1 Degrading Bacterium from Contaminated Soil of a Former Coal Gas Plant. Syst Appl Microbiol 27:653-660 (2004).

65. Schatzmayr G, Zehner F, Täubel M, Schatzmayr D, Klimitsch A, Loibner AP and Binder EM, Microbiologicals for deactivating mycotoxins. Mol Nutr Food Res 50:543-551 (2006).

66. Guan S, He J, Young J, Zhu H, Li X-Z, Ji C and Zhou T, Transformation of trichothecene mycotoxins by microorganisms from fish digesta. Aquaculture 290:290 - 295 (2009).

67. Upadhaya SD, Song JY, Park MA, Seo JK, Yang L, Lee CH, Cho KJ and Ha JK, Isolation, Screening and Identification of Swine Gut Microbiota with Ochratoxin A Biodegradation Ability. Asian-Austral Jof Anim Sci 25:114-121 (2012).

68. Mansfield MA and Kuldau GA, Microbiological and molecular determination of mycobiota in fresh and ensiled maize silage. Mycologia 99:269-278 (2007).

69. Kaur R, Domergue R, Zupancic ML and Cormack BP, A yeast by any other name: Candida glabrata and its interaction with the host. Curr Opin Microbiol 8:378-384 (2005).

70. Zhu Y, Hassan YI, Watts $\mathrm{C}$ and Zhou T, Innovative technologies for the mitigation of mycotoxins in animal feed and ingredien - A review of recent patents. Anim Feed Sci Technol 216:19-29 (2016).

71. Cakmakci ML, Evans HJ and Seidler RJ, Characteristics of nitrogen-fixingKlebsiella oxytoca isolated from wheat roots. Plant and Soil 61:53-63 (1981).

72. Franche $\mathrm{C}$, Lindström $\mathrm{K}$ and Elmerich $\mathrm{C}$, Nitrogen-fixing bacteria associated with leguminous and non-leguminous plants. Plant and Soil 321:35-59 (2009). 
73. Santos AO, Avila CL, Pinto JC, Carvalho BF, Dias DR and Schwan RF, Fermentative profile and bacterial diversity of corn silages inoculated with new tropical lactic acid bacteria. J Appl Microbiol 120(2):266-279 (2016).

74. Rosenblueth $\mathrm{M}$, Martinez L, Silva J and Martinez-Romero E, Klebsiella variicola, a novel species with clinical and plant-associated isolates. Syst Appl Microbiol 27:27-35 (2004).

75. Rossi F and Dellaglio F, Quality of silages from Italian farms as attested by number and identity of microbial indicators. J Appl Microbiol 103:1707-1715 (2007).

76. Wambacq E, Vanhoutte I, Audenaert K, De Gelder L and Haesaert G, Occurrence, prevention and remediation of toxigenic fungi and mycotoxins in silage: a review. J Sci Food Agric 96(7):2284-2302 (2016).

77. Mokoena MP, Chelule PK and Gqaleni N, Reduction of fumonisin B1 and zearalenone by lactic acid bacteria in fermented maize meal. J Food Protect 68:2095-2099 (2005).

78. Fodor J, Meyer K, Gottschalk C, Mamet R, Kametler L, Bauer J, Horn P, Kovacs F and Kovacs M, In vitro microbial metabolism of fumonisin B1. Food Addit Contam 24:416-420 (2007).

79. Schatzmayr G, Täubel M, Vekiru E and Binder EM, Microorganism for decontaminating fumonisins and its use, method for decontaminating fumonisins and feed additives containing said microorganisms. EP Patent Publication 1860954 B1 (2012). 


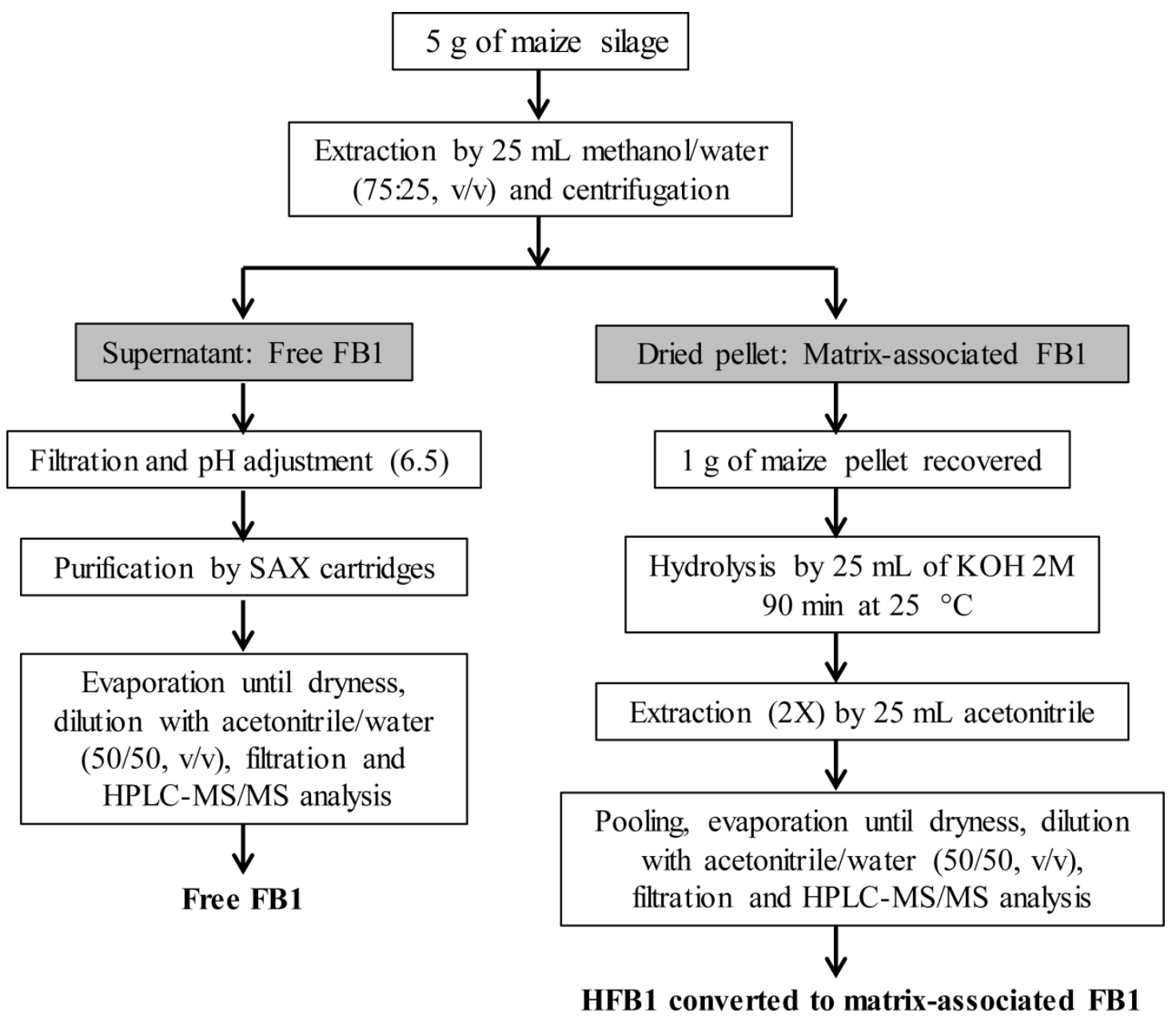

Figure 1: Flow chart of the analytical procedure used to quantify free and matrix-associated FB1 in high moisture maize grain silage 


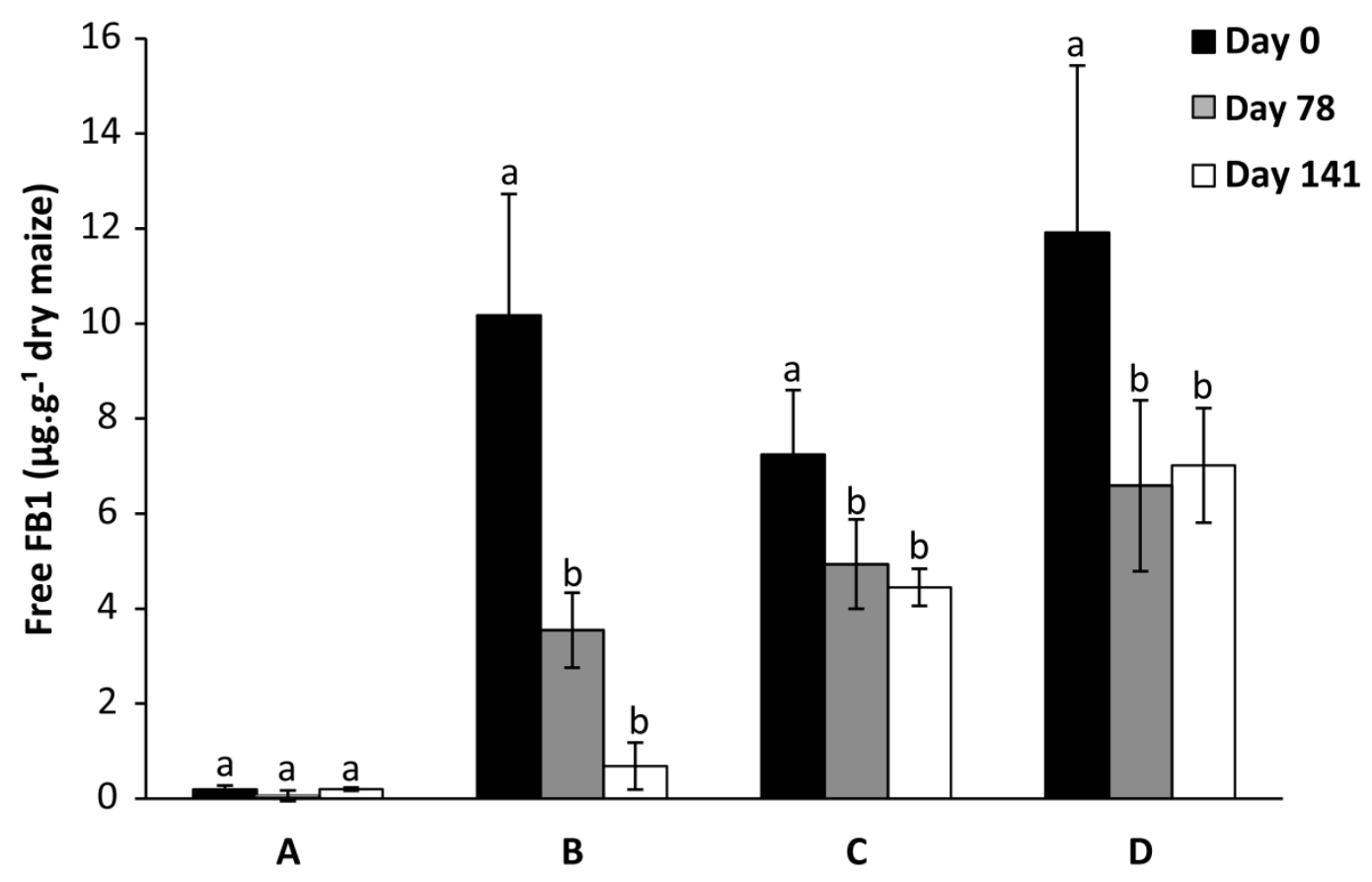

Figure 2: Evolution of free FB1 concentration during maize grain ensiling from harvest 2011. Silages A to D were prepared using different proportions of contaminated and sound maize: A (uniquely composed of sound maize), B-C (composed of $80 \%$ and $20 \%$ of sound and contaminated maize, respectively) and D (composed of $70 \%$ and $30 \%$ of sound and contaminated maize, respectively). Data are means \pm standard deviation using three analytical replicates. Different letters designate statistically significant differences between data from a same silage $(\alpha=0.05)$. 


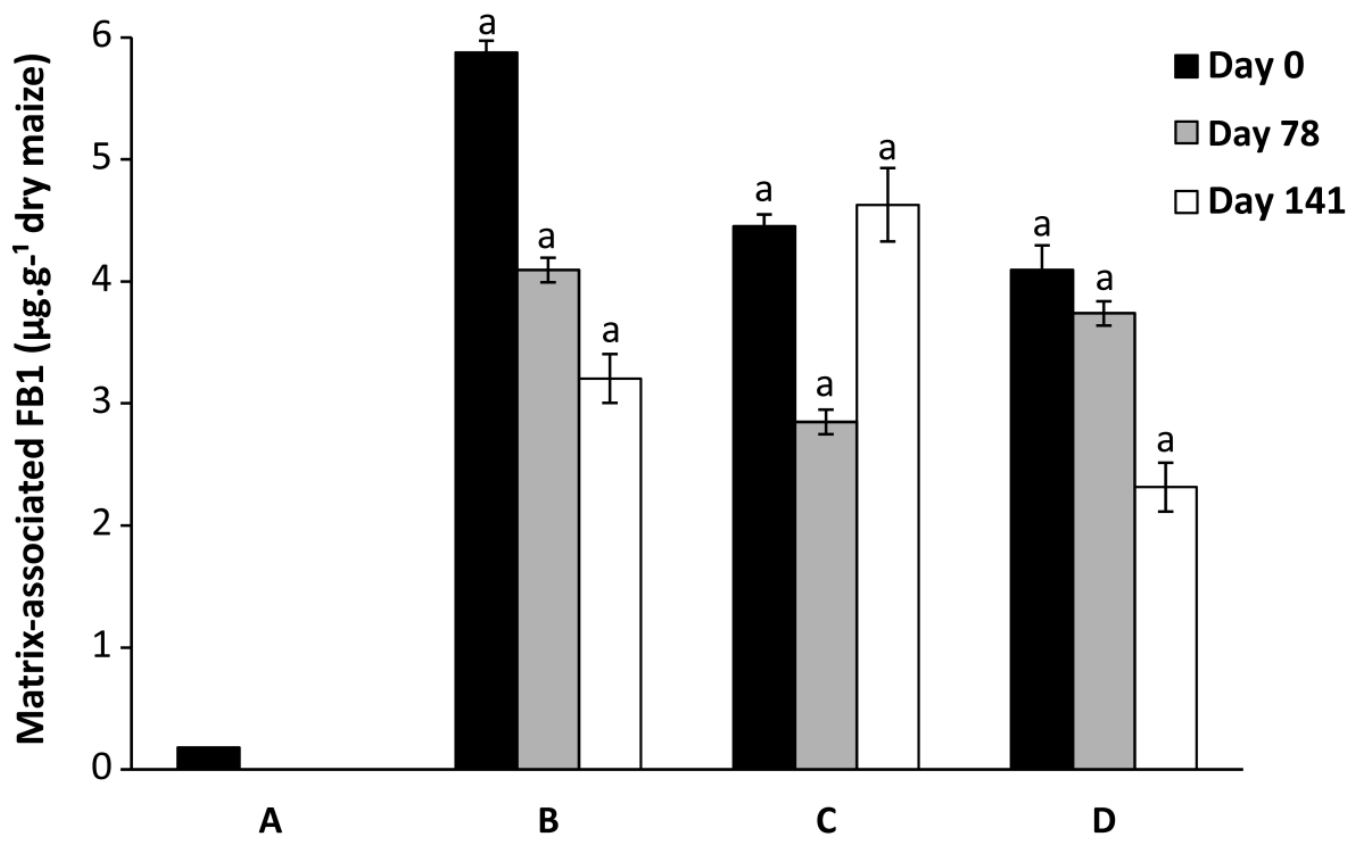

Figure 3: Evolution of matrix-associated FB1 concentration during maize grain ensiling from harvest 2011. Data are means \pm standard deviation using three analytical replicates. Different letters designate statistically significant differences between data from a same silage $(\alpha=0.05)$. 

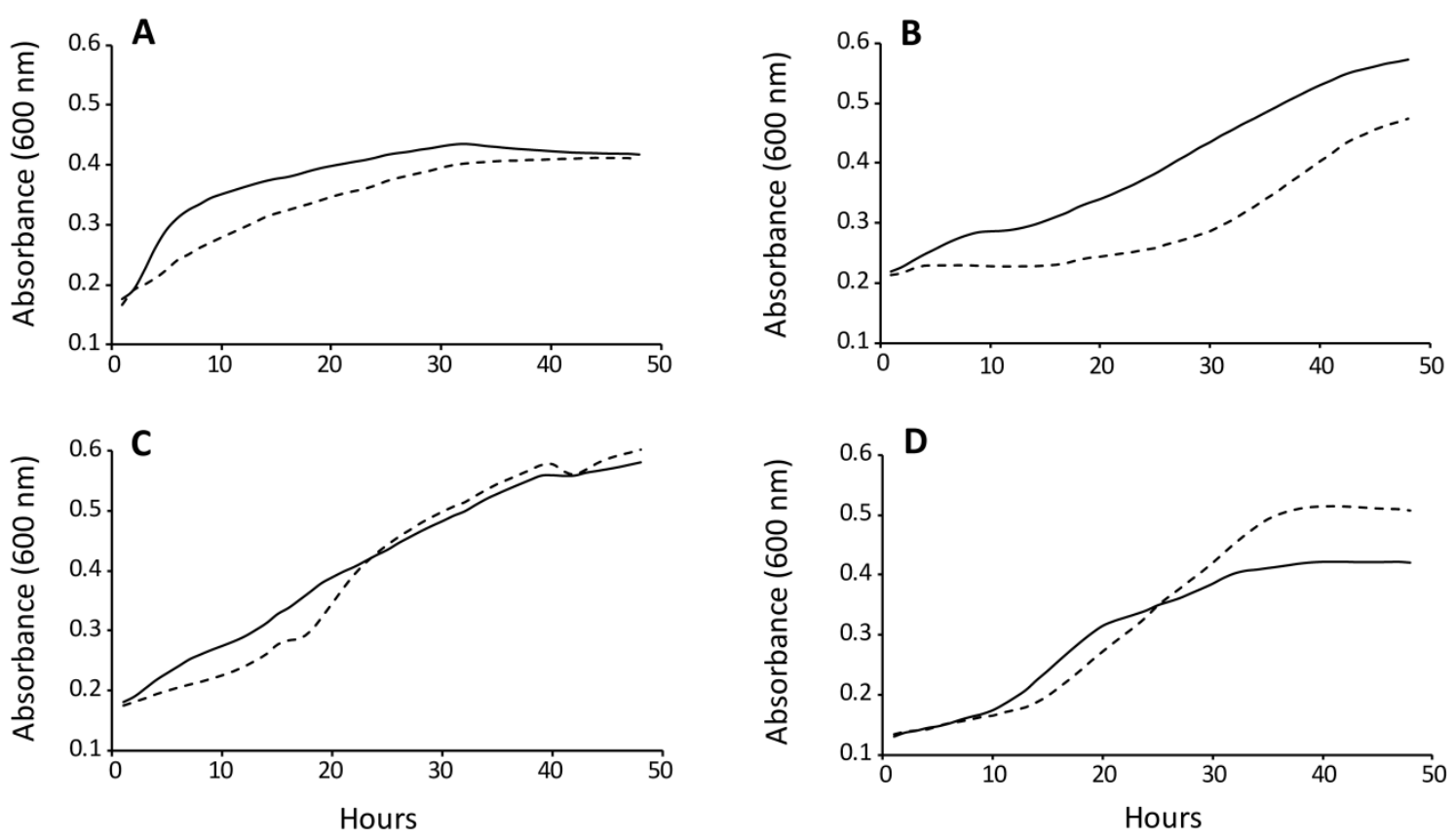

Figure 4: Typical microbial growth kinetics during $48 \mathrm{~h}$ of incubation. In black line, FB1supplemented microbial cultures (test). In dotted line, microbial cultured not supplemented with FB1 (control). Statistically significant differences between both treatments were examined after $28 \mathrm{~h}$ of incubation (t-student test, $\alpha=0.05$ ). A and B isolates were considered positive to the test. $\mathrm{C}$ and $\mathrm{D}$ considered as negatives. 
Table 1: Retention time and compound dependent parameters for LC-MS analysis of free FB1 and HFB1 in HMMG silages.

\begin{tabular}{ccccccc}
\hline Compound & $\begin{array}{c}\text { Retention } \\
\text { time }(\mathbf{m i n})\end{array}$ & $\begin{array}{c}\text { Precursor ion } \\
(\boldsymbol{m} / \boldsymbol{z})[\mathbf{M}+\mathbf{H}]^{+}\end{array}$ & $\begin{array}{c}\text { Product ions } \\
(\boldsymbol{m} / \boldsymbol{z})\end{array}$ & $\begin{array}{c}\text { Declustering } \\
\text { potential }(\mathbf{V})\end{array}$ & $\begin{array}{c}\text { Collision } \\
\text { energy }(\mathbf{V})\end{array}$ & $\begin{array}{c}\text { Cell exit } \\
\text { potential }(\mathbf{V})\end{array}$ \\
\hline FB1 & 8.9 & 722.4 & $334.4 / 352.3$ & 121 & $45 / 49$ & $6 / 6$ \\
HFB1 & 6.1 & 406.4 & $388.3 / 370.3$ & 121 & $23 / 23$ & $16 / 16$ \\
\hline
\end{tabular}


Table 2: Evolution of free FB1 and matrix-associated FB1 in silages processed with maize harvested in 2013 and percentage of matrix-associated FB1 at day 0 .

\begin{tabular}{|c|c|c|c|c|c|c|}
\hline \multirow[t]{3}{*}{ Silage } & \multicolumn{2}{|c|}{ Free FB1, $\mu \mathrm{g} . \mathrm{g}^{-1}$} & \multirow{2}{*}{\multicolumn{2}{|c|}{$\begin{array}{c}\text { Matrix-associated FB1, } \\
\mu{\mathrm{g} . \mathrm{g}^{-1}}^{-1}\end{array}$}} & \multirow{3}{*}{$\begin{array}{c}\text { \% of matrix- } \\
\text { associated FB1 } \\
\text { at day } 0^{*}\end{array}$} & \multirow{3}{*}{$\begin{array}{c}\text { \% of whole } \\
\text { FB1 } \\
\text { loss at day } 141\end{array}$} \\
\hline & \multicolumn{2}{|c|}{ Days after fermentation } & & & & \\
\hline & $\mathbf{0}$ & 141 & $\mathbf{0}$ & 141 & & \\
\hline $\mathbf{E}$ & $22.2 \pm 2.0$ & $7.8 \pm 0.5$ & $5.3 \pm 0.1$ & $5.0 \pm 0.3$ & 19.3 & 53.4 \\
\hline $\mathbf{F}$ & $16.3 \pm 0.8$ & $7.5 \pm 0.6$ & $0.9 \pm 0.1$ & $1.4 \pm 0.1$ & 5.2 & 48.2 \\
\hline G & $20.3 \pm 2.4$ & $5.1 \pm 2.0$ & $8.9 \pm 0.5$ & $8.5 \pm 0.3$ & 30.5 & 53.4 \\
\hline $\mathbf{H}$ & $9.9 \pm 0.9$ & $2.4 \pm 0.5$ & $3.4 \pm 0.3$ & $4.6 \pm 0.3$ & 25.6 & 47.4 \\
\hline
\end{tabular}

Silages E to H were prepared using grains harvested in 2013 from four fields showing Fusarium ear rot symptoms, located in the Southwest of France. "Percentage of matrix-associated FB1 at day 0 calculated according to the formula: matrix-associated FB1/(matrix-associated FB1+ free FB1)*100. Data are means \pm standard deviations using three analytical replicates. 
Table 3: In vitro characterization of microbial cultures for their ability to degrade FB1

\begin{tabular}{|c|c|c|c|c|}
\hline & Isolate & $\begin{array}{c}\text { Accession number } \\
\text { obtained after } \\
\text { BLAST analysis }\end{array}$ & $\begin{array}{c}\text { FB1 loss after } 4 \\
\text { days of } \\
\text { incubation }(\%)^{*}\end{array}$ & $\begin{array}{c}\text { Conversion of FB1 } \\
\text { into HFB1 }(\%)\end{array}$ \\
\hline \multicolumn{2}{|c|}{ Lactobacillus brevis. N195 } & NC_008497.1 & 33 & 16 \\
\hline \multicolumn{2}{|c|}{ Lactobacillus brevis N197 } & KP773479.1 & 30 & 17 \\
\hline \multicolumn{2}{|c|}{ Klebsiella variicola VA26 } & LC049203.1 & 22 & ND \\
\hline \multicolumn{2}{|c|}{ Bacillus sp. N339 } & KM819175.1 & 21 & ND \\
\hline \multicolumn{2}{|c|}{ Klebsiella oxytoca N186 } & LC049201.1 & 15 & ND \\
\hline \multicolumn{2}{|c|}{ Candida glabrata $\mathrm{N} 353$} & LC015357.1 & 7 & ND \\
\hline \multicolumn{2}{|c|}{ Candida glabrata $\mathrm{N} 345$} & LC015357.1 & 7 & ND \\
\hline \multicolumn{2}{|c|}{ Candida glabrata N346 } & LC015357.1 & 6 & ND \\
\hline \multicolumn{2}{|c|}{ Pichia fermentans N183 } & KM029994.1 & 6 & ND \\
\hline \multirow{2}{*}{$\begin{array}{l}\text { Reference } \\
\text { strains }\end{array}$} & Exophiala spinifera & ATCC74269 & 82 & 49 \\
\hline & Bacterium & ATCC55552 & 65 & 52 \\
\hline
\end{tabular}

ND: Not detected. Percentage of FB1 loss after 4 incubation days. 